\title{
Roles of calcium gradients in hyphal tip growth: a mathematical model
}

\author{
Carlos M. Regaladot \\ Fax : +34922 318334.e-mail: cregalad@mcs.dundee.ac.uk
}

Depto Bioquímica y Biología Molecular, Facultad de Biologia, Universidad de La Laguna, 38206 La Laguna, Tenerife, Islas Canarias, Spain

\begin{abstract}
A tip-high $\mathrm{Ca}^{2+}$ gradient is observed in growing fungal hyphae, but so far its role remains unknown. A mathematical model is presented, which provides evidence for the functions of such a $\mathrm{Ca}^{2+}$ gradient, in terms of its non-linear effect on the visco-elastic properties of the hyphal cytoskeleton. The model explains how the $\mathrm{Ca}^{2+}$ status at the tip may be responsible for the apical accumulation of vesicles and for an increase in the cytogel osmotic pressure, accompanied by the contraction of the cytoskeleton. The experimentally observed retraction of the spitzenkorper preceding the initiation of a branch is also reproduced, by simulating a subapical transient release of $\mathrm{Ca}^{2+}$ from internal stores.
\end{abstract}

Keywords : calcium gradients, cytoskeleton, spitzenkörper, branching, mathematical modelling

\section{INTRODUCTION}

Many tip-growing cells, such as neurons, pollen tubes and rhizoids, have cytoplasmic gradients of $\mathrm{Ca}^{2+}$ associated with polarized growth, and fungal hyphae are no exception. $\mathrm{Ca}^{2+}$ is involved in the regulation of many cellular processes, such as appressorium formation, hyphal extension and branching, and cytoplasmic migration (Jackson \& Heath, 1993; Harold, 1994, and references therein); hence the importance of this discovery. In the particular case of fungi, the measurement of $\mathrm{Ca}^{2+}$ has proved to be a difficult task (Read et al., 1992b). For example, hyphae loaded with fluorescent dyes either stop growing or show abnormal morphologies (Read et al., 1992a). Despite this fact, in all the cases where it has been possible to measure free cytoplasmic $\mathrm{Ca}^{2+}$ concentrations, a tip-high $\mathrm{Ca}^{2+}$ gradient has been found, correlated with growth (Hyde \& Heath, 1997) and absent in non-growing hyphae (Read et al., 1992a; Garrill et al., 1993; Jackson \& Heath, 1993; Hyde \& Heath, 1997). The gradient is very steep within $3 \mu \mathrm{m}$ of the apex and decays very rapidly towards a lower level, at about $10-20 \mu \mathrm{m}$ (Jackson \& Heath, 1993; Hyde \& Heath, 1997). The gradient is affected by the exogenous $\mathrm{Ca}^{2+}$ concentration, such that low

tCorrespondence to Carlos M. Regalado, do N. V. Torres, at the address shown.

Part of this work was developed while the author was a PhD student at the Centre for Non-linear Systems in Biology, Cellular and Environmental Physiology Department, Scottish Crop Research Institute, Invergowrie, Dundee, DD2 5DA, UK. external concentrations lead to a much shallower intracellular gradient (see Fig. 1 of Jackson \& Heath, 1993). By contrast, membrane-associated $\mathrm{Ca}^{2+}$ exhibits a gradient which is steeper not at the apex itself, but about $2 \cdot 5-10 \mu \mathrm{m}$ behind the apex (Yuan \& Heath, 1991). Both the origin and role of these gradients are unknown, although there is evidence that may explain their establishment and function.

With respect to the role of the $\mathrm{Ca}^{2+}$ gradient, evidence suggests that this may be involved in both hyphal extension and branching. As a rule of thumb, low extracellular $\mathrm{Ca}^{2+}$ concentrations $\left(0-10^{-7} \mathrm{M}\right)$ lead to increased branching and diminish tip elongation, while concentrations of exogenous $\mathrm{Ca}^{2+}$ above $10^{-6} \mathrm{M}$ inhibit branching and induce hyphal elongation (Robson et al., 1991; Jackson \& Heath, 1989; Schmid \& Harold, 1988; Gow et al., 1992). These effects are thought to be related to the influence that the exogenous $\mathrm{Ca}^{2+}$ has on the steepness of the intracellular $\mathrm{Ca}^{2+}$ gradient (Jackson \& Heath, 1993; Hyde \& Heath, 1997). However, the mechanism of how this may occur and what other factors may initiate hyphal branching remain unknown.

The role of $\mathrm{Ca}^{2+}$ in tip extension and branching is further supported by the results obtained with hyperbranching mutants of Neurospora crassa. These exhibit slow growth, increased branching frequency and lack of a membrane-associated $\mathrm{Ca}^{2+}$ gradient. However, high levels of exogenous $\mathrm{Ca}^{2+}$ restore their growth rate and branching pattern to that of the wild-type (Dicker $\&$ Turian, 1990).

It is the intention of this paper to extend upon previous 
work (Regalado et al., 1997; C. Regalado \& B. Sleeman, unpublished) on the role of the hyphal cytoskeleton on the distribution of wall vesicles, by incorporating the effect of an ionic species $\left(\mathrm{Ca}^{2+}\right)$ on the mechanical status of the cytoskeleton. A mathematical model previously developed (Regalado et al., 1997; C. Regalado \& B. Sleeman, unpublished) is extended to incorporate this effect. The role of $\mathrm{Ca}^{2+}$ is then investigated by considering the consequences that different $\mathrm{Ca}^{2+}$ gradients have on the distribution of wall vesicles, osmotic pressure, hyphal extension and branching initiation. Most of the mathematical analysis has been removed, in order to make the paper accessible to a wider audience. However, although the paper should be self-contained, the reader would benefit from consulting the mathematical details of the model published elsewhere.

\section{THE MODEL}

\section{Cytoskeleton mechanical forces}

The cytoskeleton is constitutively formed by polymeric filaments (see Heath, 1995, and references therein). It is this filamentous nature of the cytoskeleton components, their tendency to flow in the embeded cytoplasm and to cross-link, that gives the cellular interior its mechanical (viscoelastic) properties (see Luby-Phelps, 1994, for a review). The cytoskeleton responds elastically to its deformation because of the filamentous nature and cross-linking of its components (microtubules and actin filaments); by contrast, steric impediments to the free motion of filaments are the origin of viscous forces (Pollard \& Cooper, 1986; Janmey et al., 1988, 1991; Luby-Phelps, 1994). As in previous papers, here the cytoskeleton is described in terms of average quantities and not in its detailed molecular structure (Oster et al., 1983; Goodwin \& Trainor, 1985; Regalado et al., 1997; C. Regalado \& B. Sleeman, unpublished). Thus classical viscous and elastic parameters - shear $(\zeta)$ and bulk $(\eta)$, viscosities and Lamé coefficients $(\mu$ and $\lambda)$, respectively - will be used to characterize cytoskeletal forces.

We can write according to Newton's second law that the sum of forces (i.e. viscous, elastic and other forces) is equal to the acceleration of the cytoskeletal network $\left(\vec{u}_{t t}\right)$ times the cytoskeleton mass contained in a unit volume $(m)$. Now if one assumes the different mechanical forces acting in the cytoskeleton to be in equilibrium, we have (Goodwin \& Trainor, 1985; Regalado, 1997):

$$
\begin{aligned}
m \vec{u}_{t t} & =\overrightarrow{0}=\text { viscous }+ \text { elastic }+ \text { other forces } \\
& =\mu \Delta \vec{u}+(\lambda+\mu) \nabla(\nabla \cdot \vec{u}) \\
& +(\nabla \mu) \cdot(\nabla \vec{u})+(\nabla \vec{u}) \cdot(\nabla \mu)+(\nabla \lambda)(\nabla \cdot \vec{u}) \\
& +\eta \Delta \vec{u}_{t}+(\xi+\eta / 3) \nabla\left(\nabla \cdot \vec{u}_{t}\right) \\
& +(\nabla \eta) \cdot\left(\nabla \vec{u}_{t}\right)+\left(\nabla \vec{u}_{t}\right) \cdot(\nabla \eta)+\left(\nabla \cdot \vec{u}_{t}\right) \nabla(\xi-2 \eta / 3) \\
& -\nabla \cdot(\Gamma \tilde{l})
\end{aligned}
$$

where the zero equality reflects the equilibrium condition. $\tilde{I}$ is the unit tensor. On the right-hand side of equation (1) terms involving the time derivative (subscript $t$ ) of $\vec{u}$ (which characterizes displacements or deformations within the cytoskeleton) are associated with viscous flows, while others correspond to elastic deformations.

\section{Modelling the effect of calcium}

The degree of polymerization and interconnectivity of cytoskeletal filaments are both controlled by the cell, catalysed by microtubule-associated proteins and actinbinding proteins. The cytoskeleton, microtubuleassociated proteins and actin-binding proteins are all regulated by $\mathrm{Ca}^{2+}$ ions (Jackson \& Heath, 1993, and references therein). For example, the polymerization of actin filaments is controlled by $\mathrm{Ca}^{2+}$ ions. Thus one of the main functions of $\mathrm{Ca}^{2+}$ is the regulation of the cytoskeleton network. Hence variations in the $\mathrm{Ca}^{2+}$ concentration ultimately translate into changes in the mechanical (rheological) status of the cytoskeleton, via the modification of the cytoskeletal network by associated proteins. Although this process is complex, a hypothesis is that it can be modelled by making elastic $(\mu, \lambda)$ and viscous $(\eta, \xi)$ coefficients to depend upon the $\mathrm{Ca}^{2+}$ concentration in some characteristic fashion which qualitatively describes such regulations (Goodwin \& Trainor, 1985). The form of such dependences is discussed next.

\section{The form of the elasticity parameters}

The solation-contraction hypothesis assumes that there exists a resistance of the cytoskeleton to contract when actin filaments are cross-linked (gel state), since the filaments cannot easily slide (Taylor et al., 1979). As the $\mathrm{Ca}^{2+}$ concentration is increased within the range $10^{-8}$ $10^{-6} \mathrm{M}$, the affinity of actin-binding proteins decreases and the activation of fragmenting proteins initiates what is known as gel breakdown. Thus a decrease in both cytoplasmic viscosity and elasticity is expected. When the concentration of cytosolic free $\mathrm{Ca}^{2+}$ rises to the micromolar level, the cross-links are dissociated (sol state), allowing the actin filaments to freely slide by interaction with mechanochemical enzymes, such as myosins (McGoldrick et al., 1995). Consequently the actin filaments shorten due to contraction and the cytoskeleton becomes more resistant to deformation. This translates into an increase in the elasticity of the cytoskeletal network. For $\mathrm{Ca}^{2+}$ concentrations above $4-5 \mu \mathrm{M}$ the progressive depolymerization of filaments leads to the solation of the cytoplasm and consequently to a decay in the cytoskeletal elasticity. Taking into consideration the above observations the elasticity parameter takes the form shown in Fig. 1(a).

\section{The form of the viscosity parameters}

With respect to the form of the viscosity parameters, to the author's knowledge the effects that $\mathrm{Ca}^{2+}$ may have on the cytoskeleton viscosity have not been investigated 

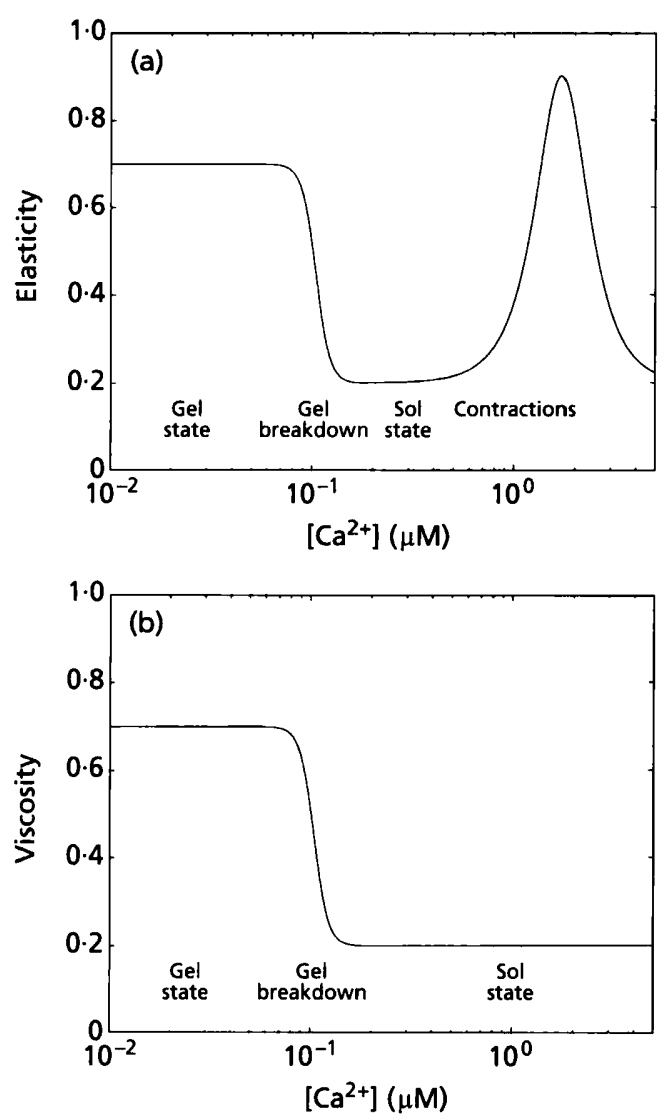

Fig. 1. Qualitative form of (a) the elasticity parameter and (b) the viscosity parameter as the $\mathrm{Ca}^{2+}$ concentration varies (see text for an explanation).

in fungi. A decrease in viscosity was reported in actin filaments isolated from macrophages for free $\mathrm{Ca}^{2+}$ concentrations above $10^{-1} \mu \mathrm{M}$ (see Fig. 4 of Yin et al., 1980). Similar results were obtained in in vivo experiments with Amoeba proteus (Gollnick et al., 1991). The form of the elasticity and viscosity parameters is plotted in Fig. 1(a) and (b), respectively. Note that the exact form of these two functions is not critical for the conclusions obtained below, as long as the overall behaviour (switching in viscosity when $\mathrm{Ca}^{2+}$ is in the micromolar range, high contraction frequencies for increasing $\mathrm{Ca}^{2+}$ concentrations, etc.) is conserved.

\section{Contractions and the form of $\Gamma$}

The internal $\mathrm{Ca}^{2+}$ concentration not only controls the rheological properties of the cytoskeleton but also initiates cytoskeletal contractions (Gollnick et al., 1991; Deloubresse et al., 1991), which may be explained in terms of 'gel-sol' transitions of the cytoskeleton as a consequence of variations in $\mathrm{Ca}^{2+}$ concentration (Taylor et al., 1979). This justifies the inclusion of the term $\nabla \cdot \Gamma \tilde{I}$ in equation (1), where $\Gamma$ describes the form of such $\mathrm{Ca}^{2+}$ dependent cytoskeletal contractions. Cytoplasmic contractions have been observed in fungi (McKerracher (a)
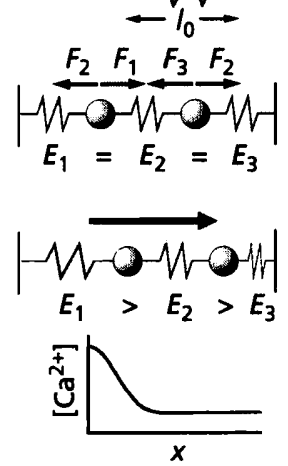

(b)
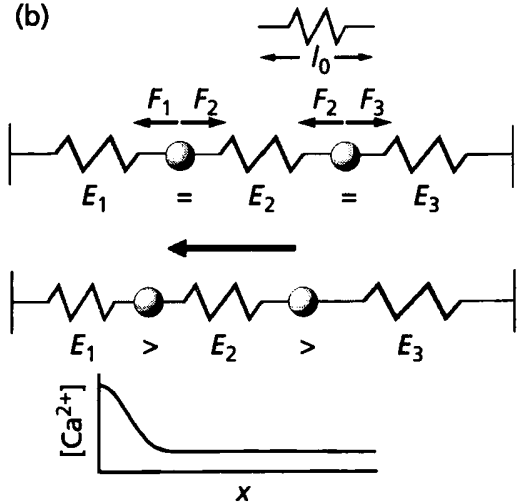

Fig. 2. The origin of $\mathrm{Ca}^{2+}$-mediated contractions is illustrated by considering an array of two vesicles separated from each other by three elastic springs, of length $I_{0}$ when unstretched. $F_{i}$ is the force exerted by spring $i$; arrows indicate the direction of this force. In (a) the system is initially in a compressed state (i.e. the equilibrium spring length is less than the unstretched length, $\left.I_{0}\right)$, whereas in (b) it is stretched. Evaluation of the forces, $F_{j,}$ in each case shows that if the elastic constant $E$ of each spring is affected in a different proportion by the $\mathrm{Ca}^{2+}$ distribution (shown in the graphs at the bottom), vesicles will be displaced towards either the right (a) or the left (b).

\& Heath, 1986a, b; Kaminskyj et al., 1992; Jackson \& Heath, 1992). They are thought to be responsible for the tipward movement of the cytoplasm in growing hyphae (Jackson \& Heath, 1989), thus allowing the cytoplasm to keep pace with the growth of the hyphal tip (McKerracher \& Heath, 1986b, 1987). Cytoplasmic contractions have been also related to the initiation of branching (Reynaga-Peña et al., 1995, 1996) and the stability of the spitzenkörper (Murphy \& Bracker, 1996; López-Franco \& Bracker, 1996).

In order to illustrate the form of $\Gamma$, we consider a onedimensional system consisting of an array of two spheres (representing e.g. wall vesicles) separated from each other by three elastic springs (which may correspond to e.g. actin filaments), of length $l_{0}$ when unstretched, and stiffness $E$, and inmersed in a viscous liquid (the cytoplasm). The system is now deformed, such that in the deformed state, the equilibrium stretched length of each spring is $l_{\text {eq }} \neq l_{0}$. The only forces prevailing in the equilibrium (no-motion state) are elastic forces, since viscous forces are solely velocity dependent. And therefore according to Hooke's law, we can write $\Gamma=E \varepsilon_{\mathrm{eq}}$, where $\varepsilon_{\mathrm{eq}}=\left(l_{\mathrm{eq}}-l_{0}\right) / l_{\mathrm{eq}}$. Notice that the sign of $\varepsilon_{\mathrm{eq}}$ changes depending on whether in the equilibrium state the system is under compression (i.e. $\varepsilon_{\mathrm{eq}}<0$ ) or tension (i.e. $0<\varepsilon_{\mathrm{eq}}<1$ ). That fungal cytoplasm is under tension was shown by monitoring nuclear movement in response to microtubule depolymerization by UV microbeam irradiation (McKerracher \& Heath, 1986a). Thus $\varepsilon_{\mathrm{eq}}$ is expected to be non-zero.

If the liquid in which the system is immersed is now supplemented with $\mathrm{Ca}^{2+}$ ions, which affect the elastic constant $E_{\mathrm{n}}$ of each spring, then unbalanced forces 
('contractions') will arise as a consequence of $\mathrm{Ca}^{2+}$ concentration gradients. A simple evaluation of the forces acting on each vesicle shows that two different scenarios are obtained depending on whether the system is stretched or compressed in the equilibrium. In the first case vesicles will be displaced towards the spring with the biggest elastic constant, while in the second case vesicles will be displaced away from this (Fig. 2).

\section{RESULTS}

The existence of a tip-to-base free $\mathrm{Ca}^{2+}$ gradient in fungal cells has been confirmed by several authors (Garrill et al., 1993; Jackson \& Heath, 1993; Levina et al., 1995). The steepness of the cytoplasmic free $\mathrm{Ca}^{2+}$ gradient is affected by the exogenous $\mathrm{Ca}^{2+}$, such that a much shallower gradient is observed for low external $\mathrm{Ca}^{2+}$ concentrations. In order to understand the role of a $\mathrm{Ca}^{2+}$ gradient at the tip, the scenarios described in the following sections will be considered.

\section{The existence of an established calcium gradient at the tip: $\left[\mathrm{Ca}^{2+}\right]_{\text {tip }}<10^{-6} \mathrm{M}$ (low)}

Conditions of decreased $\mathrm{Ca}^{2+}$ influx caused by ion chelation (Jackson \& Heath, 1989; Robson et al., 1991), by the use of $\mathrm{Ca}^{2+}$ channel blockers (Garrill et al., 1993; Dicker \& Turian, 1990), or by lowering the concentration of exogenous $\mathrm{Ca}^{2+}$ concentration (Jackson \& Heath, 1989; Yuan \& Heath, 1991; Hyde \& Heath, 1997), lead to a reduction in hyphal extension rate, tip swelling and enhanced branching. In those experiments where it was monitored, a reduced influx of external $\mathrm{Ca}^{2+}$ led to a decrease in the membrane-associated (Jackson \& Heath, 1989; Robson et al., 1991) and free (Garrill et al., 1993; Jackson \& Heath, 1993) internal $\mathrm{Ca}^{2+}$ gradients.

From the form of the elasticity and viscosity coefficients in Fig. $1(a, b)$ it is predicted that for low $\mathrm{Ca}^{2+}$ concentrations $\left(<10^{-6} \mathrm{M}\right)$ the accumulation of vesicles would be favoured at the base of the tip (Fig. 3). This is also reflected in Fig. 4, which shows the vesicle aggregation dynamics under low $\mathrm{Ca}^{2+}$ concentrations. Starting with an initially homogeneous vesicle distribution, cytoskeletal strains drive the vesicle population (spitzenkörper) towards the Golgi side. Videomicroscopy analysis of growing hyphae shows that the dislocation of the spitzenkörper from its polar position is normally accompanied by morphological changes at the tip (bulbous or rounded tips and branch formation) and a reduction or halting of tip growth (BartnickiGarcia et al., 1995a, b; Reynaga-Peña et al., 1995, 1996; Murphy \& Bracker, 1996). Thus low $\mathrm{Ca}^{2+}$ concentrations would correspond to a situation of diminished tip extension rate and increased subapical branching frequency. Also since the delivery of vesicles to the tip apex would come from a retracted position of the vesicle supply centre, we expect an abnormal tip morphology: rounded and bulbous tips. These morphological characteristics are predicted by the model and correspond with the above-discussed experimental observations in conditions of low $\mathrm{Ca}^{2+}$ concentration.

Very low external $\mathrm{Ca}^{2+}$ may not simply lead to an internal decrease in the endogenous $\mathrm{Ca}^{2+}$ concentration. For example, in Saprolegnia ferax, depletion of the exogenous $\mathrm{Ca}^{2+}$ to levels of the order of $10^{-11} \mathrm{M}$ showed that hyphae mantain a cytoplasmic $\mathrm{Ca}^{2+}$ gradient that peaks $10 \mu \mathrm{m}$ behind the tip, rather than at the apex itself (see Fig. 10 of Hyde \& Heath, 1997). This situation is simulated here in Fig. 5. This shows that inversion of the tip-high $\mathrm{Ca}^{2+}$ gradient favours the subapical accumulation of wall vesicles, a result which is consistent with the observed decrease in hyphal growth under these conditions (Hyde \& Heath, 1997). Several effects may be responsible for this slow growth (see below).

\section{The existence of an established calcium gradient at the tip: $\left[\mathrm{Ca}^{2+}\right]_{\text {tip }}<2 \times 10^{-6} \mathrm{M}$ (optimal)}

When the exogenous $\mathrm{Ca}^{2+}$ concentration is in the range $10^{-5}-10^{-2} \mathrm{M}$, hyphal elongation rate is increased, apical morphology is normal and branching frequency is reduced (Garrill et al., 1993; Robson et al., 1991). Its effect on the internal $\mathrm{Ca}^{2+}$ is to create a steeper gradient of free $\mathrm{Ca}^{2+}$ at the apex (Jackson \& Heath, 1993).

From the form of the elasticity parameter in Fig. 1(a), it is expected that, for $\mathrm{Ca}^{2+}$ concentrations in the range 1-2 $\mu \mathrm{M}$, vesicles will accumulate preferentially at the apical pole (Figs 6 and 8), following a gradient of decreasing cytoskeletal strain. At the apex the high $\mathrm{Ca}^{2+}$ concentration favours the dissociation of cytoskeletal cross-links, and therefore of a solled state, while subapically the lower $\mathrm{Ca}^{2+}$ concentration increases the number of filament entanglements (gel state). This represents a situation where vectorial growth is enhanced, for the following reasons.

First, at the base of the tip the cytoskeletal gelled state provides a scaffolding that strengthens the hyphal tube. Because of its cross-linked nature, the gel will also transmit tension from contracting regions.

Secondly, fragmentation of the actin meshwork at the apex of the tip increases the number of free filaments and therefore their capacity to diffuse freely. Strain is minimal apically, which also contributes to the filaments' freedom to adopt different configurations. These two effects together have an associated consequence: due to the increment in entropy (Oster, 1984), the internal osmotic pressure is raised. Thus the tip wall is pushed forward by the osmotic expansion of the cytoskeleton at the apex.

Thirdly, the elastic force ( $\left.F_{\text {elas }}\right)$ is proportional to the cytoskeletal deformation or strain $(\varepsilon)$ - Hooke's law. Hence from equation (1) it is found (Regalado, 1997) that as time progresses the elastic force tends to the equilibrium situation: $F_{\text {elas }}=P-\bar{\lambda} \varepsilon_{\text {eq }}$, where $P$ is some traction force exerted at the wall (e.g. by turgor pressure) and $\bar{\lambda}$ has the form shown in Fig. 6(d). Experiments suggest that the cytoplasm is under tension even in the absence of $\mathrm{Ca}^{2+}$ (McKerracher \& Heath, 1986a, and 

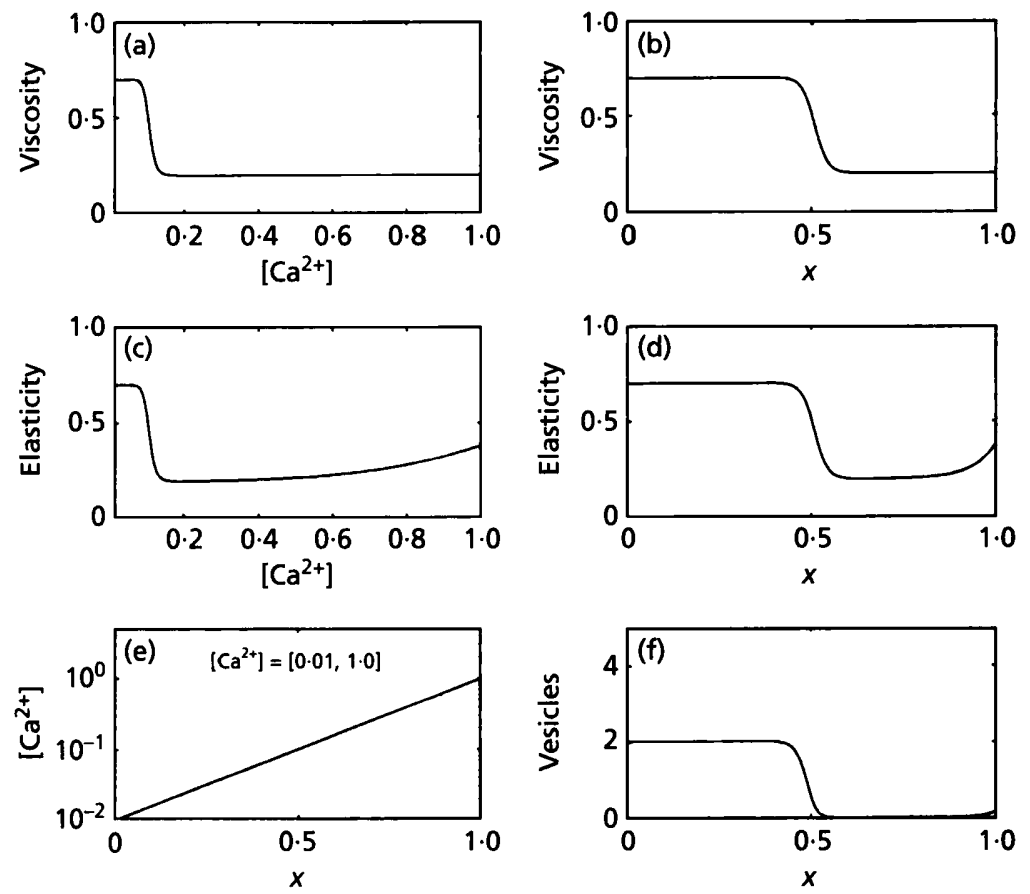

Fig. 3. The form of the viscosity $(a, b)$ and elasticity (c, d) parameters, and the predicted stationary vesicle distribution ( $f$ ) for the $\mathrm{Ca}^{2+}$ gradient shown in $(\mathrm{e}):\left[\mathrm{Ca}^{2+}\right]$ at the apex, $C a_{1}=1.0 \mu \mathrm{M}$, and subapical $\left[\mathrm{Ca}^{2+}\right], C a_{0}=0.01 \mu \mathrm{M}$. The $x$ represents $a$ normalized distance from subapical regions, such that 0 corresponds to the Golgi side and 1 to the apical wall.

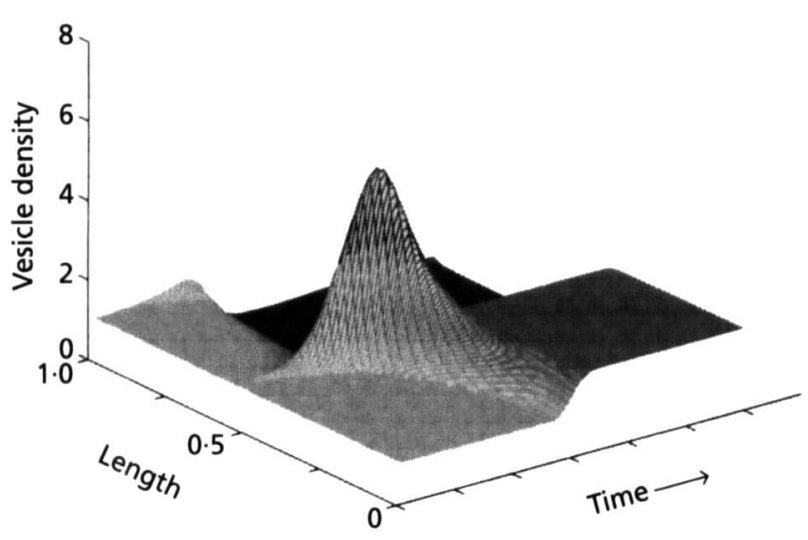

Fig. 4. As predicted by the stationary vesicle distribution (see Fig. 3f), vesicles aggregate backward from the apex when the cytoplasmic $\mathrm{Ca}^{2+}$ concentration is low. $\mathrm{Ca}^{2+}$ gradient as in Fig. 3(e): $\left[\mathrm{Ca}^{2+}\right]$ at the apex, $\mathrm{Ca}=1.0 \mu \mathrm{M}$, and subapical $\left[\mathrm{Ca}^{2+}\right]$, $C a_{0}=0.01 \mu \mathrm{M}$. Initially vesicles aggregate in a more apical position, but very rapidly these are recruited at the Golgi side. 'Length' represents a normalized distance from subapical regions, such that 0 corresponds to the Golgi side and 1 to the apical wall.

references therein). This implies that $\varepsilon_{\mathrm{eq}}>0$ (see above). Therefore the elastic restoring force decays towards the apex, and thus eventually this will be overcome by the rise in osmotic pressure at the apical pole.

Fourthly, during growth the cytoplasm must move forward in order to keep pace with the growth of the tip (McKerracher \& Heath, 1986b, 1987). Cytoplasmic contractions are thought to be responsible for such cytoplasmic translocation (Jackson \& Heath, 1989). In the range $1-2 \mu \mathrm{M} \mathrm{Ca}^{2+}$, solation is sufficient to allow filament sliding and contraction. Contractions generate a hydrostatic pressure gradient, as the cytoskeleton filaments are dragged forward through the cytoplasm, that can be quite substantial (Odell, 1977). This may lead to fibre alignment (thus favouring vesicle motion), and can compress and push the cytoplasm forward, as observed in the contracting hyphae of Rbizoctonia solani (López-Franco \& Bracker, 1996), thus helping the cytoplasm to move into the growing region.

Finally, since the vesicle supply centre is placed apically, the delivery of wall material necessary for tip elongation is ensured. The model therefore predicts that vectorial growth is favoured in this $\mathrm{Ca}^{2+}$ concentration range $(1-2 \mu \mathrm{M})$, while branching is diminished, as has been experimentally observed (see above).

Figs 7 and 9 show the vesicle aggregation dynamics under micromolar apical $\mathrm{Ca}^{2+}$ concentrations. Starting from a homogeneous vesicle distribution, vesicles aggregate mainly at the apex as time progresses. However if the $\mathrm{Ca}^{2+}$ concentration falls to submicromolar levels at the Golgi side, a subapical vesicle aggregation is also observed (Fig. 9). In the latter case the transient behaviour is similar to the example shown in Fig. 3 (with submicromolar $\left[\mathrm{Ca}^{2+}\right]$ ), resulting in an initial apical aggregation of wall vesicles followed by the collapse of the aggregation peak and the (sub)apical recruitment of vesicles.

\section{Cytoplasmic contractions and branch initiation}

How is branching initiated under such an established $\mathrm{Ca}^{2+}$ gradient? Only recently it has been possible to monitor the series of cellular events which take place during hyphal branching (Reynaga-Peña et al., 1995, 1996). Preceding the initiation of a branch a momentary cytoplasmic contraction (lasting about $1 \mathrm{~s}$ ) causes the 

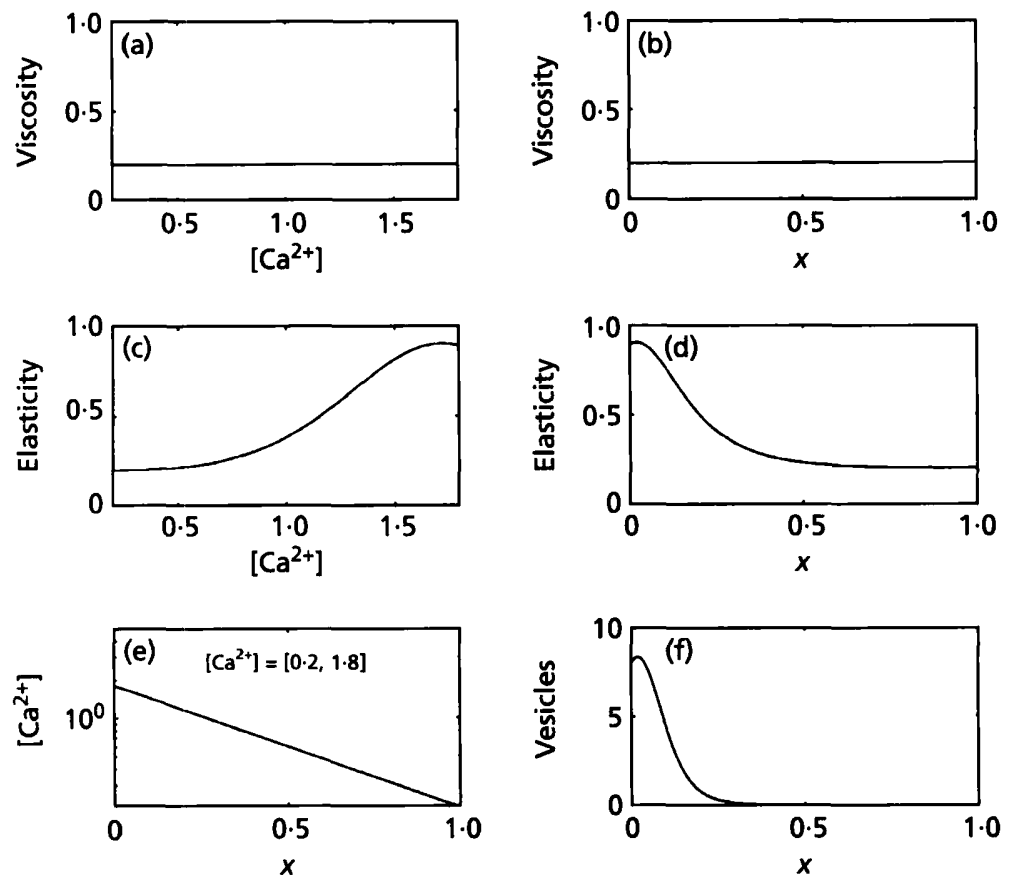

Fig. 5. The form of the viscosity ( $a, b)$ and elasticity $(c, d)$ parameters, and the predicted stationary vesicle distribution $(f)$ for the $\mathrm{Ca}^{2+}$ gradient shown in (e): $\left[\mathrm{Ca}^{2+}\right]$ at the apex, $\mathrm{Ca}_{1}=0.2 \mu \mathrm{M}$, and subapical $\left[\mathrm{Ca}^{2+}\right]$, $C a_{0}=1.8 \mu \mathrm{M}$. The inversion of the normal tip-high $\mathrm{Ca}^{2+}$ gradient leads to the subapical accumulation of vesicles. The $x$ represents a normalized distance from subapical regions, such that 0 corresponds to the Golgi side and 1 to the apical wall.
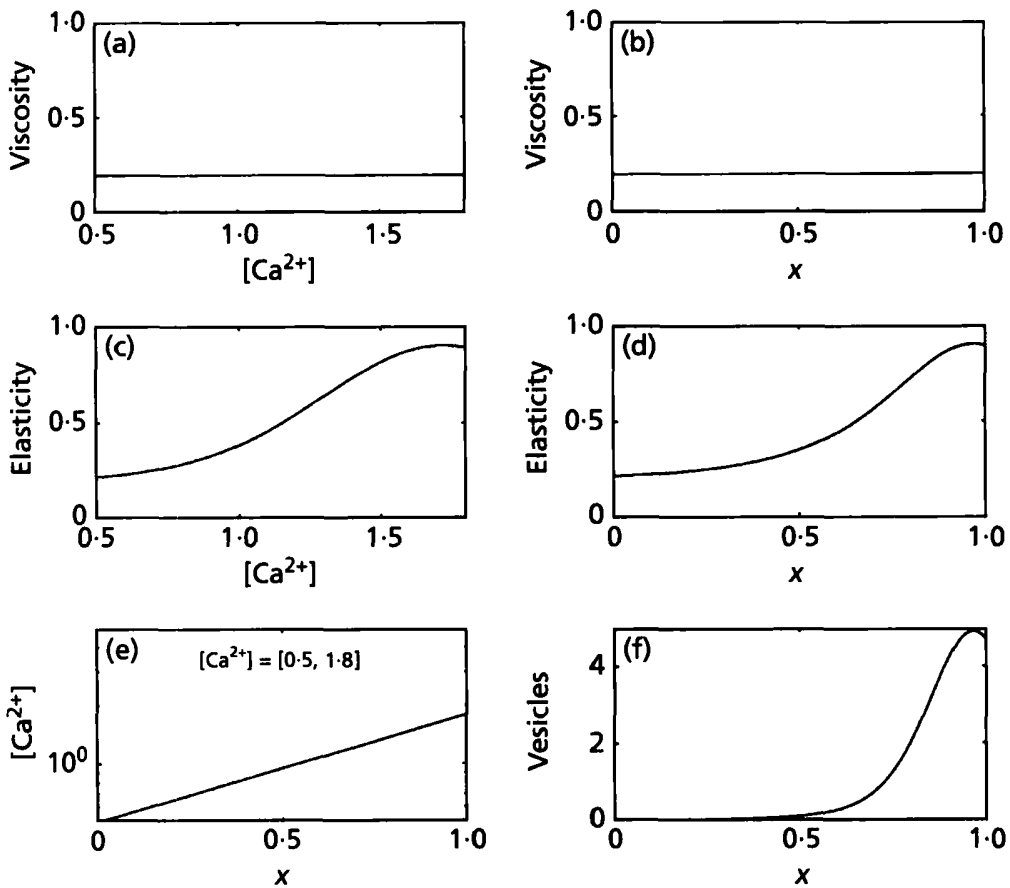

Fig. 6. The form of the viscosity $(a, b)$ and elasticity ( $c$, d) parameters, and the predicted stationary vesicle distribution (f) for the $\mathrm{Ca}^{2+}$ gradient shown in (e): $\left[\mathrm{Ca}^{2+}\right]$ at the apex, $C a_{1}=1.8 \mu \mathrm{M}$, and subapical $\left[\mathrm{Ca}^{2+}\right]$, $C a_{0}=0.5 \mu \mathrm{M}$. The $x$ represents a normalized distance from subapical regions, such that 0 corresponds to the Golgi side and 1 to the apical wall.

spitzenkörper to retract from its polar position at the apex. The spitzenkörper dislocation is concurrent with a reduction in the rate of hyphal elongation. After a period, polarized growth is recovered and instead of the original spitzenkörper, two spitzenkörper appear, giving rise to two apical branches (Aspergillus niger and Neurospora crassa) or to subapical and lateral branches (Trichoderma harzianum). Not all cytoplasmic contractions lead to a branch formation, but they do always affect the spitzenkörper positioning and branches do not form unless preceded by a contraction (Reynaga-Peña $e t$ al., 1995). Similar tipwards, $\mathrm{Ca}^{2+}$-dependent cytoplasmic contractions can also be induced by UV irradiation (McKerracher \& Heath, 1986b; Jackson \& Heath, 1992), ionophores (Kaminskyj et al., 1992), mechanical and light stress (López-Franco \& Bracker, 1996) or electric fields (López-Franco \& Bracker, 1996; Murphy \& Bracker, 1996). Such contractions seem to be independent of the existence of an internal $\mathrm{Ca}^{2+}$ gradient, since non-growing hyphae (which are expected to lack a $\mathrm{Ca}^{2+}$ gradient) showed tipwards contractions when irradiated with UV light (Jackson \& Heath, 1992). 


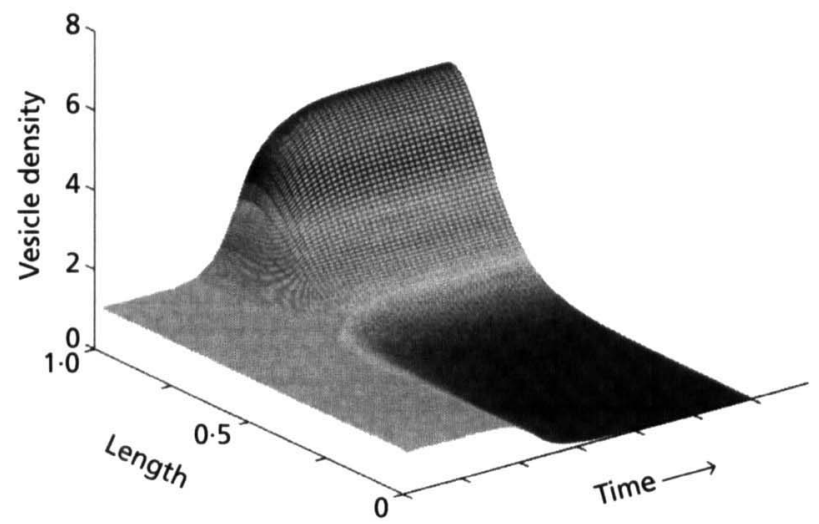

Fig. 7. When the cytoplasmic $\mathrm{Ca}^{2+}$ concentration is in the micromolar range vesicles aggregate apically. $\mathrm{Ca}^{2+}$ gradient as in Fig. 6(e): $\left[\mathrm{Ca}^{2+}\right]$ at the apex, $C a_{1}=1.8 \mu \mathrm{M}$, and subapical $\left[\mathrm{Ca}^{2+}\right], \mathrm{Ca}_{0}=0.5 \mu \mathrm{M}$. 'Length' represents a normalized distance from subapical regions, such that 0 corresponds to the Golgi side and 1 to the apical wall.

Aditionally, the ionophore A23187 (known to destroy the normal tip-to-base membrane-associated $\mathrm{Ca}^{2+}$ gradient) induces cytoplasmic contractions in Sapro. legnia (Kaminskyj et al., 1992) and Basidiobolus (McKerracher \& Heath, 1986b). However, if an internal $\mathrm{Ca}^{2+}$ gradient exists, contractions are more likely because solation would favour filament sliding. This may explain the greater effectiveness of hyphae to contract when grown in high versus low external $\mathrm{Ca}^{2+}$ conditions and when irradiated apically versus subapically (Jackson \& Heath, 1992).

When the $\mathrm{Ca}^{2+}$ concentration is in the micromolar range, subapical accumulation of vesicles is not rejected

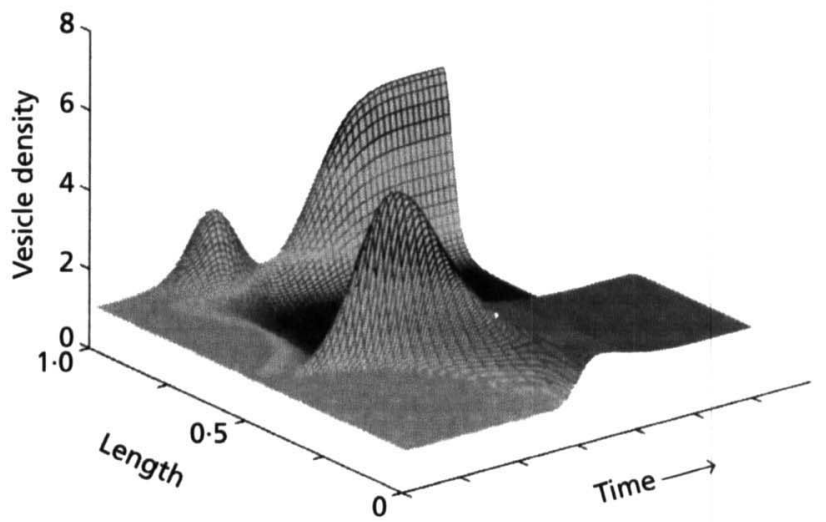

Fig. 9. Both an apical and a subapical vesicle aggregation take place when the cytoplasmic $\mathrm{Ca}^{2+}$ concentration is in the micromolar range at the wall apex and decays towards submicromolar levels at the Golgi side. $\mathrm{Ca}^{2+}$ gradient as in Fig. 8(e): $\left[\mathrm{Ca}^{2+}\right]$ at the apex, $\mathrm{Ca}_{1}=1.8 \mu \mathrm{M}$, and subapical $\left[\mathrm{Ca}^{2+}\right]$, $C a_{0}=0.01 \mu \mathrm{M}$. 'Length' represents a normalized distance from subapical regions, such that 0 corresponds to the Golgi side and 1 to the apical wall.

by the model (Figs 8 and 9), provided one considers that in regions behind the tip the $\mathrm{Ca}^{2+}$ gradient falls to submicromolar levels (Levina et al., 1995). However, another mechanism for the subapical aggregation of vesicles may be also invoked. When the $\mathrm{Ca}^{2+}$ concentration is in the order of micromolar, conditions are optimal for cytoskeletal contraction (see Fig. 1). If the cytoskeleton is under tension (as shown in McKerracher \& Heath, 1986a, and references therein), then a transient release of sequestered $\mathrm{Ca}^{2+}$ from subapical cytoplasmic organelles, such as vacuoles (Miller et al., 1990; Cornelius \& Nakashima, 1987), would initiate a sub-
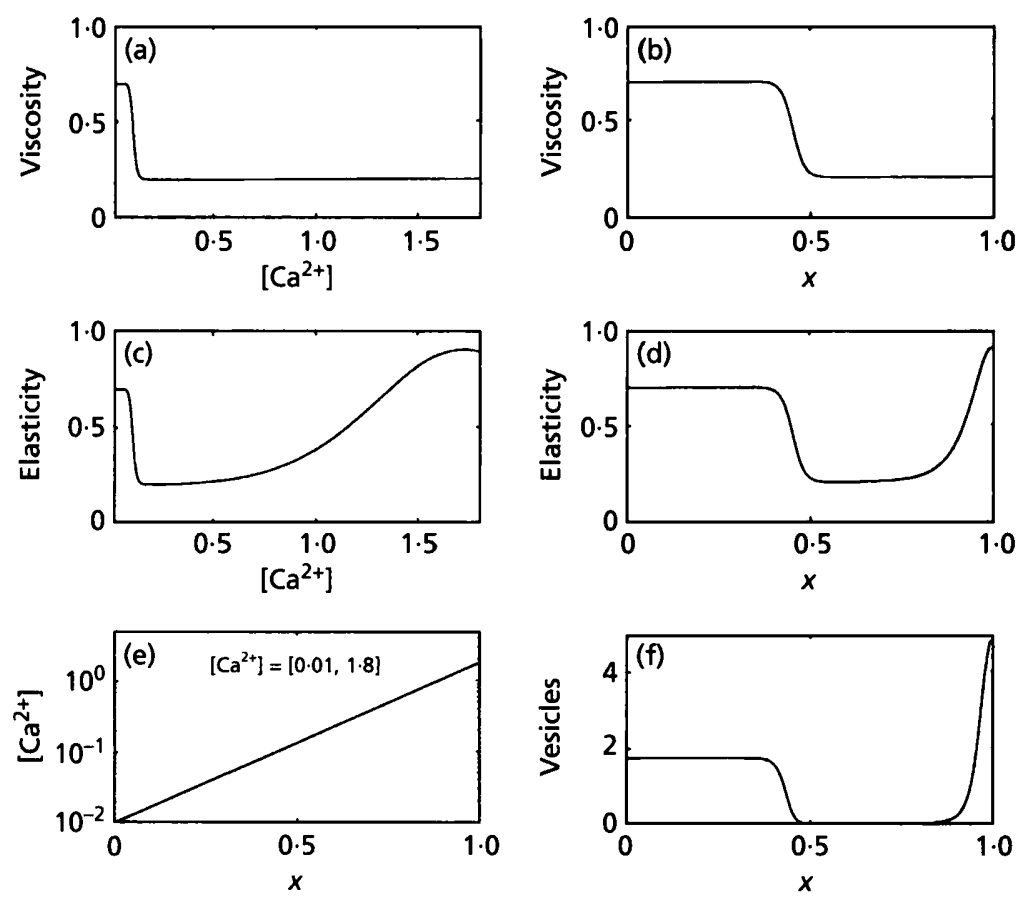

Fig. 8. The form of the viscosity (a, b) and elasticity $(c, d)$ parameters, and the predicted stationary vesicle distribution (f) for the $\mathrm{Ca}^{2+}$ gradient shown in (e): $\left[\mathrm{Ca}^{2+}\right]$ at the apex, $C a_{1}=1.8 \mu \mathrm{M}$, and subapical $\left[\mathrm{Ca}^{2+}\right], C a_{0}=0.01 \mu \mathrm{M}$. The $x$ represents a normalized distance from subapical regions, such that 0 corresponds to the Golgi side and 1 to the apical wall. 


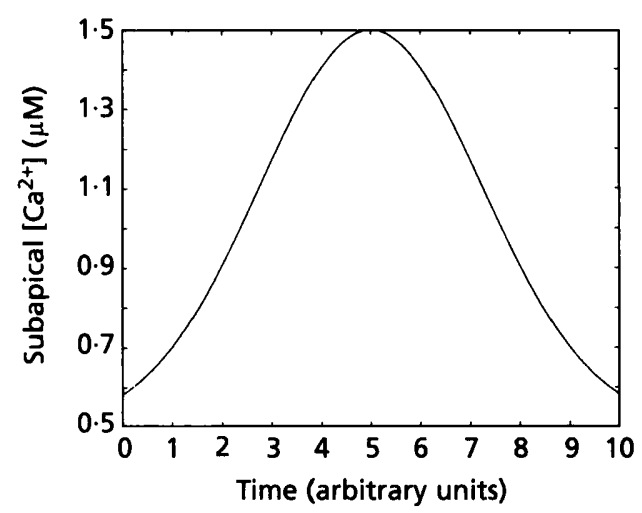

Fig. 10. A release and subsequent resequestration of $\mathrm{Ca}^{2+}$ ions from internal stores can be simulated by assuming that the subapical $\mathrm{Ca}^{2+}$ concentration varies according to the form shown in the figure. See text for details.

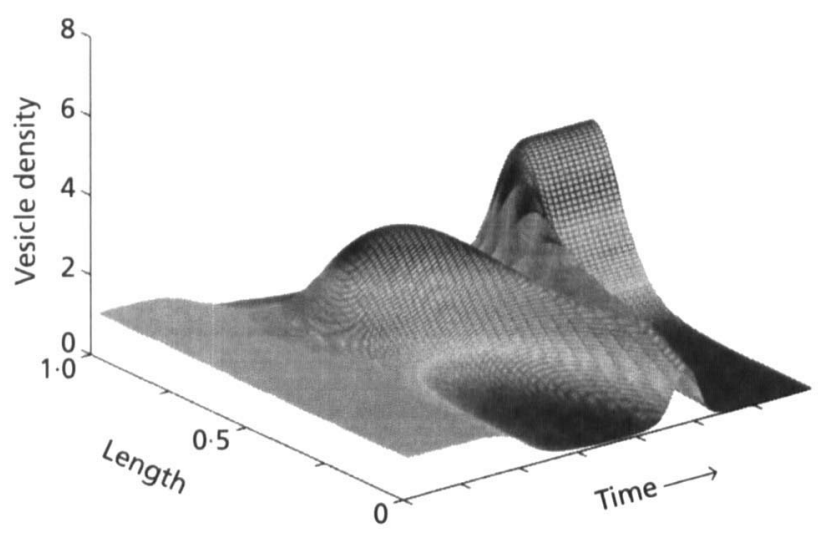

Fig. 11. The transient release of $\mathrm{Ca}^{2+}$ from subapical cytoplasmic stores may be responsible for the dislocation of the spitzenkorper - retraction from its polar position at the apex and subsequent recovery of its apical position, a phenomenon observed during branch initiation. The subapical $\mathrm{Ca}^{2+}$ concentration follows the evolution shown in Fig. 10, and the $\mathrm{Ca}^{2+}$ concentration at the apex, $\mathrm{Ca}_{1}$, is taken to be $3.0 \mu \mathrm{M}$. 'Length' represents a normalized distance from subapical regions, such that 0 corresponds to the Golgi side and 1 to the apical wall.

apical cytoskeletal contraction pulling the spitzenkörper backwards (see Fig. 2).

In order to test such a possibility, of a retraction of the spitzenkörper and subsequent relaxation to its original position by a release and posterior resequestration of $\mathrm{Ca}^{2+}$ ions (see above), let us assume that the subapical $\mathrm{Ca}^{2+}$ concentration, $\mathrm{C} a_{0}$, varies according to

$C a_{0}(t)=\left(C a_{\mathrm{M}}-C a_{\mathrm{m}}\right) \mathrm{e}^{-k\left(t-t_{\mathrm{M}}\right)^{2}}+C a_{\mathrm{m}}$

where $\mathrm{Ca} a_{M}$ is the maximum subapical free $\mathrm{Ca}^{2+}$ concentration achieved by release from the internal stores after some time $t_{\mathrm{M}}, \mathrm{Ca}$ is the basal free $\mathrm{Ca}^{2+}$ concentration before release and after resequestration, and $k$ is an arbitrary constant which determines how fast the free $\mathrm{Ca}^{2+}$ concentration approaches and departs from $C a_{M}$ (Fig. 10). Fig. 11 shows an example of such a scenario, with $C a_{\mathrm{m}}=0.5, C a_{\mathrm{M}}=1.5, k=0.1$ and $t_{\mathrm{M}}=$ 5 . After an initial vesicle aggregation, the spitzenkörper moves towards subapical regions (as the $\left[\mathrm{Ca}^{2+}\right]$ increases at the Golgi side), subsequently recovering its apical position as $\mathrm{Ca}^{2+}$ is resequestered. This suggests that a transient release of $\mathrm{Ca}^{2+}$ from subapical stores may be responsible for the spitzenkörper dislocation, e.g. preceding the initiation of a branch (see above). This theoretical prediction has been reinforced with the recent demonstration of a transient elevation of free $\mathrm{Ca}^{2+}$ concentration by UV irradiation of Saprolegnia ferax hyphae (Hyde \& Heath, 1997). The increase in $\mathrm{Ca}^{2+}$ concentration is higher $10 \mu \mathrm{m}$ behind the tip, thus suggesting a release of $\mathrm{Ca}^{2+}$ from subapical stores. But UV irradiation also caused an overall increase in the $\mathrm{Ca}^{2+}$ concentration (see Fig. 11 and Table 1 of Hyde \& Heath, 1997). Fig. 12 shows the effect that varying both the apical and subapical $\mathrm{Ca}^{2+}$ concentration has on the distribution of wall vesicles. It can be seen that an overall increase in $\mathrm{Ca}^{2+}$ concentration favours the subapical accumulation of vesicles, a likely situation after UV treatment of hyphae, since growth is halted and the hyphae are more rounded. Notice that such spitzenkörper retraction is not achieved, or is less pronounced, when the $\mathrm{Ca}^{2+}$ concentration is increased at one end only (Fig. 12).

The sequence of cellular events following UV irradiation, that is, cessation of growth after $2-2.5 \mathrm{~min}$ accompanied by a change in hyphal morphology (presumably because of spitzenkörper retraction) and followed by resumption of growth, is almost identical to that observed preceding branch initiation (compare Fig. 11 of Hyde \& Heath, 1997, with Fig. 1 of Reynaga-Peña et al., 1997). The same event sequence is also observed after treatment with cytochalasins (Grove \& Sweigard, 1981) or the application of electric fields (López-Franco $\&$ Bracker, 1996). Interestingly, cytochalasins induce branching (Harold \& Harold, 1986) and the galvanotropic response of hyphae is $\mathrm{Ca}^{2+}$-dependent (Gow, 1995, p. 291, and references therein). In all the above instances cytoplasmic contractions have been observed, further suggesting that the contractions that precede branch initiation, and that dislodge the spitzenkörper from its apical position, may be due to a transient $\mathrm{Ca}^{2+}$ signal.

\section{The existence of an established calcium gradient at the tip: $\left[\mathrm{Ca}^{2+}\right]_{\text {tip }}>4 \times 10^{-6} \mathrm{M}$ (high)}

Fungi grown on high- $\mathrm{Ca}^{2+}$ media $\left(>10^{-2} \mathrm{M}\right)$ show inhibited tip extension and a very diffuse cytoskeleton network which contains little actin and a greater level of membrane-associated $\mathrm{Ca}^{2+}$. Although there is the possibility of an artifact, hyphae of Saprolegnia ferax grown on $\mathrm{Ca}^{2+}$-free media also showed a very high concentration of free $\mathrm{Ca}^{2+}$ (Hyde \& Heath, 1997).

An increase in the $\mathrm{Ca}^{2+}$ concentration above 4-5 $\mu \mathrm{M}$ would push the elasticity values towards the decreasing region in Fig. 1(a). Consequently the aggregation centre would be dislodged from its apical position towards a 

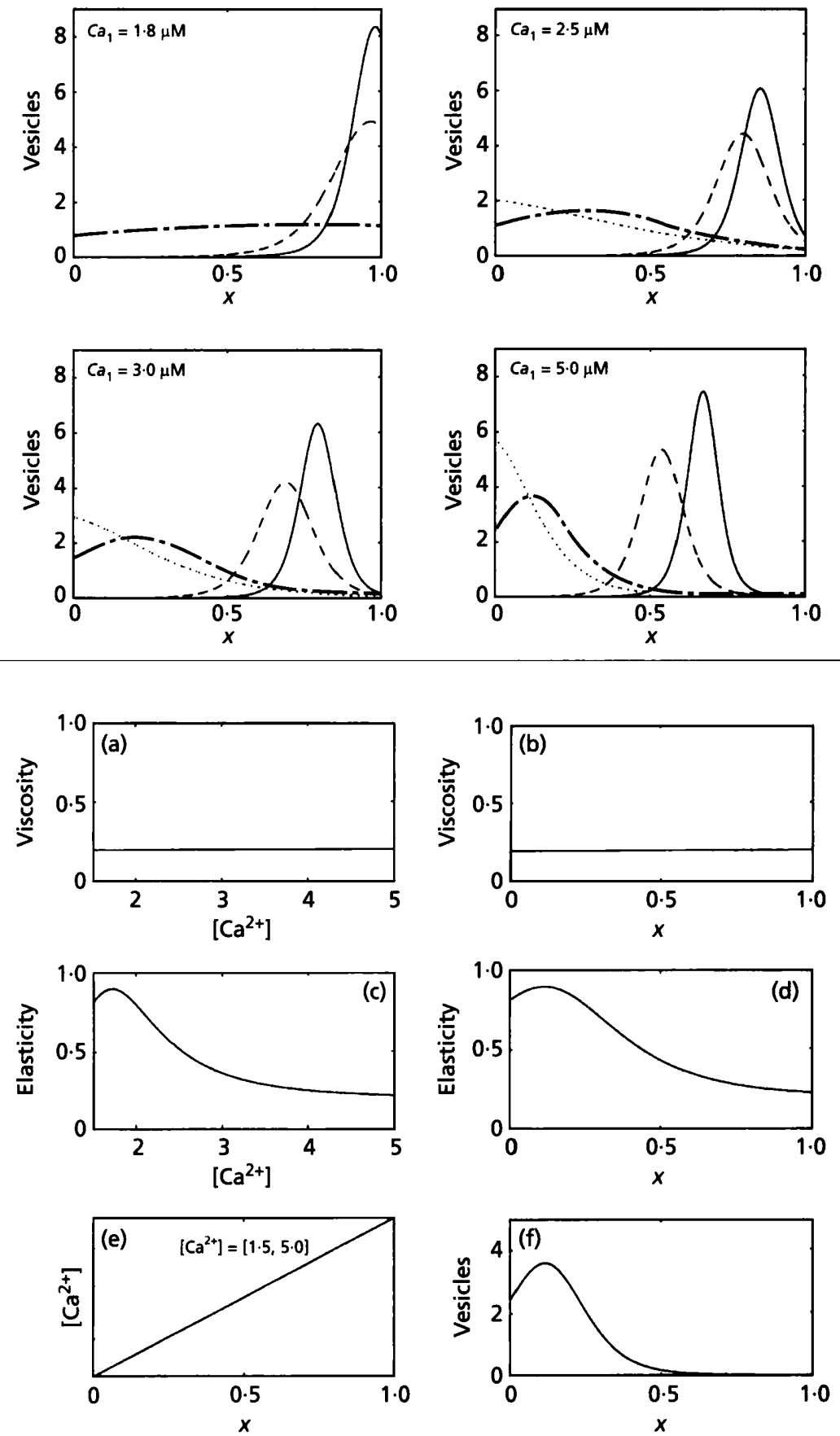

Fig. 12. A release of sequestered $\mathrm{Ca}^{2+}$ from subapical cytoplasmic organelles favours the accumulation of vesicles in subapical regions. The plots show predicted stationary vesicle distribution for different apical $\mathrm{Ca}^{2+}$ concentrations, $\mathrm{Ca}_{1}$, while varying the $\mathrm{Ca}^{2+}$ concentration at the Golgi side. The different line types correspond to different subapical $\left[\mathrm{Ca}^{2+}\right], \mathrm{Ca}_{0}$ : solid, $0.2 \mu \mathrm{M}$; dashed, $0.5 \mu \mathrm{M}$; dashed-dotted, $1.5 \mu \mathrm{M}$; dotted, $1.8 \mu \mathrm{M}$. The $x$ represents a normalized distance from subapical regions, such that 0 corresponds to the Golgi side and 1 to the apical wall. more subapical region, following a declining gradient in cytoplasmic strain. Vesicles will encounter a cytoskeletal strain that is greater ahead of them, than towards the subapical regions, and therefore the vesicles will move 'backwards', driven by a minimum strain potential criterion (see Regalado, 1997, Fig. 3.22). Interestingly, fixation of Saprolegnia hyphal tips moved the mostapical saltatory vesicles significantly away from the apex (Kaminskyj et al., 1992). The effect of fixatives, as of other contraction-inducing treatments, is probably due to upsetting of the ion $\left(\mathrm{Ca}^{2+}\right)$ homeostasis.

Fig. 13 shows the form of the cytoskeleton viscoelastic parameters and the predicted stationary wall vesicle distribution under a high $\mathrm{Ca}^{2+}$ concentration. Such a vesicle pattern is confirmed by numerical simulation in Fig. 14, showing the subapical accumulation of vesicles when the $\mathrm{Ca}^{2+}$ concentration is high.

Under high $\mathrm{Ca}^{2+}$ concentrations $\left(>4 \times 10^{-6} \mathrm{M}\right)$ the fragmentation of the cytoskeleton is almost complete (Fig. 1). Therefore we would expect, as before, an increment in the internal osmotic pressure and consequently an expansion of the tip. However, such an increase in the cytogel osmotic force is not accompanied by the necessary polarized supply of wall material and therefore tip extension will be arrested. On the contrary, a bulbous tip morphology would be expected. However, 


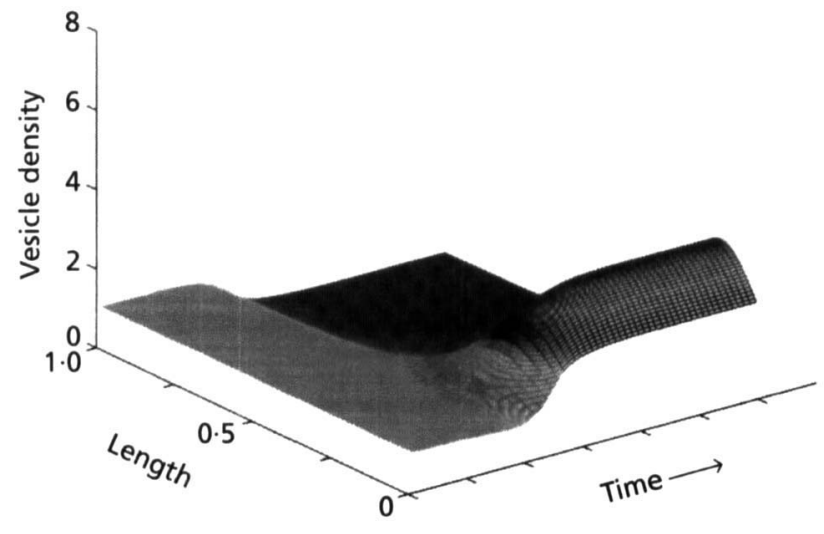

Fig. 14. Under high $\mathrm{Ca}^{2+}$ concentrations vesicles aggregate subapically. $\mathrm{Ca}^{2+}$ gradient as in Fig. $\left.13(\mathrm{e}): \mathrm{Ca}^{2+}\right]$ at the apex, $C a_{1}=5.0 \mu \mathrm{M}$, and subapical $\left[\mathrm{Ca}^{2+}\right], C a_{0}=1.5 \mu \mathrm{M}$. 'Length' represents a normalized distance from subapical regions, such that 0 corresponds to the Golgi side and 1 to the apical wall.

when grown in high- $\mathrm{Ca}^{2+}$ conditions, cells are also bathed in a higher $\mathrm{Ca}^{2+}$ level and this could provoke an increase in wall rigidity (Tagawa $\&$ Bonner, 1957). This may explain the observed normal cell morphology, compared to that of hyphae grown in low- $\mathrm{Ca}^{2+}$ conditions, which were irregularly shaped (Jackson \& Heath, 1989). A more rigid wall will also require higher internal osmotic pressure to enable tip extension. Thus the increased wall rigidity will also contribute to the inhibition of growth and prevent budding.

\section{DISCUSSION}

Tip growth is the result of the orchestrated variety of processes which includes mechanical coordination, wall extensibility and strength, ionic control, polarized delivery of wall material, cytoplasm migration, and osmotic pressure regulation. This paper presents a model which incorporates some of these aspects, such as wall vesicle motion, cytoskeleton mechanics and its regulation by $\mathrm{Ca}^{2+}$ ions. The results obtained with the model agree with a wide range of experimental observations and in some instances suggest plausible explanations for some of these. For example, the greater effectiveness of Saprolegnia hyphae to contract when irradiated apically versus subapically is poorly explained in terms of UV-induced permeabilization of the plasmalemma, as acknowledged by the authors who made the observation (see Jackson \& Heath, 1992). I would argue that this is consistent with the solation of the cytoskeleton induced by the higher $\mathrm{Ca}^{2+}$ concentration at the tip and thus favouring apical filament sliding.

So far, the role of the $\mathrm{Ca}^{2+}$ gradient in hyphal tips remains unanswered. The model presented here provides evidence for the functions of such a tip-high $\mathrm{Ca}^{2+}$ gradient, in terms of its (non-linear) effect on the rheology of the cytoskeleton, thus extending the conclusions obtained in previous work on the origin of such viscoelastic forces. Additionally, and as a consequence of such non-linearity, the relationship between $\mathrm{Ca}^{2+}$ and hyphal growth is expected to be complex, a circumstance often observed experimentally (Jackson \& Heath, 1989; Hyde \& Heath, 1997). Thus, for example, the model identifies a Ca ${ }^{2+}$ 'window' for optimal growth. $\mathrm{Ca}^{2+}$ concentrations below and above such narrow range may have similar effects, i.e. slowing or halting of growth (cf. Figs 4 and 14), but for different reasons (cf. Figs 3 and 13). This has implications for the design and interpretation of experiments and calls for a combined approach using modelling experiments as a more successful way of addressing hyphal morphogenesis.

Most of the phenomena involved in tip elongation and explained by the model, such as wall vesicle aggregation or cytoplasmic contractions, arise as a consequence of the spatio-temporal dependence of the viscoelastic properties of the cytoskeleton. Thus the present work stresses the importance of a $\mathrm{Ca}^{2+}$ gradient for hyphal growth in contradistinction to the mere presence or absence of $\mathrm{Ca}^{2+}$. A constant $\mathrm{Ca}^{2+}$ distribution would lead to a homogeneous vesicle distribution, i.e. to the stoppage of growth, while steeper gradients would favour polarized growth. This is also in consonance with experimental results which show that treatments, such as UV irradiation, $\mathrm{pH}$ variations or modulation of the exogenous $\mathrm{Ca}^{2+}$ concentration, with strong morphogenetic consequences for a hypha, act via modification of the internal $\mathrm{Ca}^{2+}$ gradient, and not simply by elevating or decreasing a constant $\mathrm{Ca}^{2+}$ concentration.

In this respect the capability for regulation of the mechanical properties of the cytoskeleton is broadened by considering an ionic species. This is an important issue since tip growth requires a very precise regulation. The involvement of phenomena such as cytoskeletal contractions, cytoplasm migration and osmotic pressure also arises as a consequence of considering the influence of $\mathrm{Ca}^{2+}$. The model explains how the $\mathrm{Ca}^{2+}$ status at the tip may be responsible for the apical accumulation of vesicles and for an increase in osmotic pressure accompanied by the contraction of the cytoplasm and its migration. This strengthens the idea that tip growth should be understood in terms of concomitant effects, resulting from a series of favourable conditions that have as their final goal the extension of a cell in a polarized manner.

An important result of this work is that of providing a mechanism for the cytoplasmic contractions and subsequent dislocation of the spitzenkörper, which precede the initiation of a branch, in terms of a transient increase in the endogenous $\mathrm{Ca}^{2+}$ concentration - an idea first suggested by Reissig \& Kinney (1983). This is not to say that we fully understand the mechanism of hyphal branching, but only that we can explain and simulate some of its indispensable aspects. Something more is needed for a branch to form, since not all cytoplasmic contractions lead to branch formation. The answer to that question may come from the extension of the present model to higher dimensions. A simpler two- 
dimensional version of the model (Regalado et al., 1997) was able to reproduce the disorganization of the spitzenkörper preceding the initiation of a branch (Reynaga-Peña et al., 1997).

Although the model developed here does not rely on the hyphal cytogel osmosis to explain tip growth, it does show that an increase in osmotic pressure would be coincident with an apical localization of the spitzenkörper and that such osmotic potential is, at least in part, controlled by cytoskeletal gel-sol transitions that are $\mathrm{Ca}^{2+}$-mediated. This represents a mechanism of tip extension which describes tip growth as a combination of localized osmotic pressure and vesicle supply. Osmotic pressure is, however, not included in the model equations, and therefore its consequence for hyphal growth cannot be rigorously established. The origin of such osmotic pressure and how to include it in the present model was discussed by Regalado (1997) and will be considered in future improvements of the model.

Finally, a strong test of the model would come from the simultaneous monitoring of free $\mathrm{Ca}^{2+}$ gradient variations, spitzenkörper positioning and tip morphology in hyphae treated with $\mathrm{Ca}^{2+}$ ionophores, $\mathrm{Ca}^{2+}$ channel blockers or UV microirradiation, or grown under different exogenous $\mathrm{Ca}^{2+}$ concentrations. This would require the development of protocols that combine video-enhanced microscopy with fluorescence techniques, in dye-loaded hyphae or in cells genetically transformed with the aequorin gene.

\section{REFERENCES}

Bartnicki-Garcia, S., Bartnicki, D., Gierz, G., López-Franco, R. \& Bracker, C. (1995a). Evidence that the Spitzenkörper behavior determines the shape of a fungal hypha: a test of the hyphoid model. Exp Mycol 19, 153-159.

Bartnicki-Garcia, S., Gierz, G., Bartnicki, D., López-Franco, R. \& Bracker, C. (1995b). Disruption of tip growth in hyphae of Rbizoctonia solani: an experimental test of the hyphoid model. In Proceedings of the Annual Meeting of the Mycological Society of America, 1995.

Cornelius, G. \& Nakashima, H. (1987). Vacuoles play a decisive role in calcium homeostasis in Neurospora crassa. J Gen Microbiol 133, 2341-2347.

Deloubresse, N., Klotz, C., Vigues, B., Rutin, J. \& Beisson, J. (1991). $\mathrm{Ca}^{2+}$-binding proteins and contractility of the infracillary latice in Paramecium. Biol Cell 71, 217-225.

Dicker, J. \& Turian, G. (1990). Calcium deficiencies and apical hyperbranching in wild type and the 'frost' and 'spray' morphological mutants of Neurospora crassa. J Gen Microbiol 136, 1413-1420.

Garrill, A., Jackson, S., Lew, R. \& Heath, I. (1993). Ion channel activity and tip growth: tip-localized stretch-activated channels generate an essential $\mathrm{Ca}^{2+}$ gradient in the oomycete Saprolegnia ferax. Eur J Cell Biol 60, 358-365.

Gollnick, F., Meyer, R. \& Stockem, W. (1991). Visualization and measurement of calcium transients in Amoeba proteus by fura-2 fluorescence. Eur J Cell Biol 55, 262-271.

Goodwin, B. \& Trainor, L. (1985). Tip and whorl morphogenesis in Acetabularia by calcium regulated strain fields. J Theor Biol 117 , 79-106.
Gow, N. (1995). Tip growth and polarity. In The Growing Fungus, pp. 277-299. Edited by N. Gow \& G. Gadd. London: Chapman \& Hall.

Gow, N., Miller, P. \& Gooday, G. (1992). Life at the apex: growth of the hyphal tip. J Chem Technol Biotechnol 56, 217-219.

Grove, S. \& Sweigard, J. (1981). The Spitzenkörper core persists after tip growth is arrested by cytochalasins. Mycol Soc Am Newsl 32, 33.

Harold, F. (1994). Ionic and electrical dimensions of hyphal growth. In The Mycota. Growth, Differentiation and Sexuality, vol. 1, pp. 89-109. Edited by J. G. H. Wessels \& F. Meinhardt. Berlin \& Heidelberg: Springer.

Harold, R. \& Harold, F. (1986). Ionophores and cytochalasins modulate branching in Achyla bisexualis. J Gen Microbiol 132, 213-219.

Heath, I. (1995). The cytoskeleton. In The Growing Fungus, pp. 99-134. Edited by N. Gow \& G. Gadd. London: Chapman \& Hall.

Hyde, G. \& Heath, I. (1997). $\mathrm{Ca}^{2+}$ gradients in hyphae and branches of Saprolegnia ferax. Fungal Genet Biol 21, 238-251.

Jackson, S. \& Heath, I. (1989). Effects of exogenous calcium ions on tip growth, intracellular $\mathrm{Ca}^{2+}$ concentration, and actin arrays in hyphae of the fungus Saprolegnia ferax. Exp Mycol 13, 1-12.

Jackson, S. \& Heath, I. (1992). UV microirradiation elicits $\mathrm{Ca}^{2+}$ dependent apex-directed cytoplasmic contractions in hyphae. Protoplasma 170, 46-52.

Jackson, S. \& Heath, I. (1993). Roles of calcium ions in hyphal tip growth. Microbiol Rev 57, 367-382.

Janmey, P. \& 5 other authors (1988). Viscoelasticity of $F$ actin and F-actin/gelsolin complexes. Biochemistry 27, 8218-8226.

Janmey, P., Euteneur, U., Traub, P. \& Schllwa, M. (1991). Viscoelastic properties of vimentin compared with other filamentous biopolymer networks. J Cell Biol 113, 155-160.

Kaminskyj, S., Jackson, S. \& Heath, I. (1992). Fixation induces differential polarized translocations of organelles in hyphae of Saprolegnia ferax. J Microsc 167, 153-168.

Levina, N., Lew, R., Hyde, G. \& Heath, I. (1995). The roles of $\mathrm{Ca}^{2+}$ and plasmamembrane ion channels in hyphal tip growth of Neurospora crassa. J Cell Sci 108, 3405-3417.

López-Franco, R. \& Bracker, C. (1996). Diversity and dynamics of the Spitzenkörper in growing hyphal tips of higher fungi. Protoplasma 195, 90-111.

Luby-Phelps, K. (1994). Physical properties of cytoplasm. Curr Opin Cell Biol 6, 3-9.

McGoldrick, C., Gruver, C. \& May, G. (1995). myoA of Aspergillus nidulans encodes an essential myosin I required for secretion and polarized growth. J Cell Biol 128, 577-587.

McKerracher, L. \& Heath, I. (1986a). Fungal nuclear behavior analysed by ultraviolet microbeam irradiation. Cell Motil Cytoskeleton 6, 35-47.

McKerracher, L. \& Heath, I. (1986b). Polarized cytoplasmic movement and inhibition of saltations induced by calciummediated effects of microbeams in fungal hyphae. Cell Motil Cytoskeleton 6, 136-145.

McKerracher, L. \& Heath, I. (1987). Cytoplasmic migration and intracellular organelle movements during tip growth of fungal hyphae. Exp Mycol 11, 79-100.

Miller, A., Vogg, G. \& Saunders, D. (1990). Cytosolic calcium homeostasis in fungi: roles of plasma membrane transport and intracellular sequestration of calcium. Proc Natl Acad Sci USA 87, 9348-9352. 
Murphy, D. \& Bracker, C. (1996). Effects of electric fields on hyphal growth and Spitzenkörper in Rhtioctonia solani. In Proceedings of the Annual Meeting of the Mycological Society of America, 1996.

Odell, G. (1977). A continuum theory of Allen's frontal contraction model of amoeboid pseudopodium extension. $J$ Mechanochem Cell Motil 4, 1-13.

Oster, G. (1984). On the crawling of cells. J Embryol Exp Morphol Suppl 83, 329-364.

Oster, G., Murray, J. \& Harris, A. (1983). Mechanical aspects of mesenchymal morphogenesis. J Embryol Exp Morphol 78, 83-125.

Pollard, T. \& Cooper, J. (1986). Actin and actin-binding proteins. A critical evaluation of mechanism and functions. Annu Rev Biochem 55, 987--1035.

Read, N., Allan, W., Knight, H., Knight, M., Malho, R., Russell, A., Shacklock, P. \& Trewavas, A. (1992a). Imaging and measurement of cytosolic free calcium in plant and fungal cells. J Microsc 166, 57-86.

Read, N., Knight, H. \& Trewavas, A. (1992b). Fluorescence ratio imaging and confocal microscopy of calcium in filamentous fungi. Binary 4, 50-52.

Regalado, C. (1997). Mechanistic models for colony form in filamentous fungi. $\mathrm{PhD}$ thesis, University of Dundee.

Regalado, C., Sleeman, B. \& Ritz, K. (1997). Aggregation and collapse of fungal wall vesicles in hyphal tips: a model for the origin of the Spitzenkörper. Philos Trans R Soc Lond B 352, 1963-1974.

Reissig, J. \& Kinney, S. (1983). Calcium as a branching signal in Neurospora crassa. J Bacteriol 154, 1397-1402.

Reynaga-Peña, C., Bracker, C. \& Bartnicki-Garcia, S. (1995). Cytoplasmic contractions, Spitzenkörper behavior and apical branching in Aspergillus niger. In Proceedings of the Annual Meeting of the Mycological Society of America, 1995.

Reynaga-Pef̂a, C., López-Franco, R., Bracker, C. \& BartnickiGarcia, S. (1996). Cytoplasmic contractions in fungal hyphae and their morphogenetic consequences. In Proceedings of the Annual Meeting of the Mycological Society of America, 1996.

Reynaga-Peña, C., Gierz, G. \& Bartnicki-Garcia, S. (1997). Analysis of the role of the Spitzenkörper in fungal morphogenesis by computer simulation of apical branching in Aspergillus niger. Proc Natl Acad Sci USA 94, 9096-9101.

Robson, G., Wiebe, M. \& Trinci, A. (1991). Low calcium concentrations induce increased branching in Fusarium graminearum. Mycol Res 95, 561-565.

Schmid, J. \& Harold, F. (1988). Dual role for calcium ions in apical growth of Neurospora crassa. J Gen Microbiol 134, 2623-2631.

Tagawa, T. \& Bonner, J. (1957). Mechanical properties of the Avena coleoptile as related to auxin and to ionic interactions. Plant Physiol 32, 207-212.

Taylor, D., Hellewell, S., Virgin, H. \& Heiple, J. (1979). The solation-contraction coupling hypothesis of cell movements. In Cell Motility: Molecules and Organization, pp. 363-377. Edited by S. Hatano. New York: Academic Press.

Yin, H., Zaner, K. \& Stossel, T. (1980). $\mathrm{Ca}^{2+}$ control of actin gelation. Interaction of gelsolin with actin filaments and regulation of actin gelation. J Biol Chem 255, 9494-9500.

Yuan, S. \& Heath, I. (1991). Chlortetracycline staining patterns of growing hyphal tips of the oomycete Saprolegnia ferax. Exp Mycol 15, 103-115.

Received 1 April 1998; accepted 8 June 1998. 